\title{
Evaporation from three water bodies of different sizes and climates: Measurements and scaling analysis
}

\author{
S. Assouline ${ }^{\mathrm{a}, *}$, S.W. Tyler ${ }^{\mathrm{b}}$, J. Tanny $^{\mathrm{a}}$, S. Cohen ${ }^{\mathrm{a}}$, E. Bou-Zeid ${ }^{\mathrm{c}}$, \\ M.B. Parlange ${ }^{\text {c }}$, G.G. Katul ${ }^{\mathrm{d}}$ \\ a Institute of Soil, Water and Environmental Sciences, A.R.O. - Volcani Center, Bet Dagan, Israel \\ ${ }^{\mathrm{b}}$ Department of Geological Sciences and Engineering, University of Nevada, Reno, USA \\ ${ }^{\mathrm{c}}$ School of Architecture, Civil and Environmental Engineering, Ecole Polytechnique Federale de Lausanne (EPFL), Lausanne, Switzerland \\ ${ }^{\mathrm{d}}$ Nicholas School of the Environment and Earth Sciences, Duke University, Durham, USA
}

Received 3 May 2007; received in revised form 23 July 2007; accepted 25 July 2007

Available online 10 August 2007

\begin{abstract}
Evaporation from small reservoirs, wetlands, and lakes continues to be a theoretical and practical problem in surface hydrology and micrometeorology because atmospheric flows above such systems can rarely be approximated as stationary and planar-homogeneous with no mean subsidence (hereafter referred to as idealized flow state). Here, the turbulence statistics of temperature $(T)$ and water vapor $(q)$ most pertinent to lake evaporation measurements over three water bodies differing in climate, thermal inertia and degree of advective conditions are explored. The three systems included Lac Léman in Switzerland (high thermal inertia, near homogeneous conditions with no appreciable advection due to long upwind fetch), Eshkol reservoir in Israel (intermediate thermal inertia, frequent strong advective conditions) and Tilopozo wetland in Chile (low thermal inertia, frequent but moderate advection). The data analysis focused on how similarity constants for the flux-variance approach, $C_{T} / C_{q}$, and relative transport efficiencies $R_{w T} / R_{w q}$, are perturbed from unity with increased advection or the active role of temperature. When advection is small and thermal inertia is large, $C_{T} / C_{q}<1$ (or $R_{w T} /$ $\left.R_{w q}>1\right)$ primarily due to the active role of temperature, which is consistent with a large number of studies conducted over bare soil and vegetated surfaces. However, when advection is significantly large, then $C_{T} / C_{q}>1$ (or $R_{w T} / R_{w q}<1$ ). When advection is moderate and thermal inertia is low, then $C_{T} / C_{q} \sim 1$. This latter equality, while consistent with Monin-Obukhov similarity theory (MOST), is due to the fact that advection tends to increase $C_{T} / C_{q}$ above unity while the active role of temperature tends to decrease $C_{T} / C_{q}$ below unity. A simplified scaling analysis derived from the scalar variance budget equation, explained qualitatively how advection could perturb MOST scaling (assumed to represent the idealized flow state).
\end{abstract}

(C) 2007 Elsevier Ltd. All rights reserved.

Keywords: Advection; Flux-variance method; Lake evaporation; Monin-Obukhov similarity theory; Scalar similarity

\section{Introduction}

Evaporation from open water bodies such as wetlands and lakes often represents the largest loss in their local hydrologic budget, yet its quantification continues to be a theoretical and a practical challenge in surface hydrol-

\footnotetext{
* Corresponding author. Tel.: +972 3 9683432; fax: +972 39604017.

E-mail address: vwshmuel@agri.gov.il (S. Assouline).
}

ogy and micrometeorology. On the theoretical side, a number of micrometeorological methods such as the energy balance-Bowen ratio method and similarity theory approaches (including flux-gradient and flux-variance) $[10,11,25,35]$ have been developed to estimate surface evaporation. Both methods are well suited for high Reynolds number flows that are planar-homogeneous and stationary in the absence of subsidence (hereafter referred to as idealized flow conditions). However, non-ideal conditions remain the rule rather than the exception in such 
systems. Efficient operation and management of surface water resources, irrigated fields, or vegetated areas require accurate quantification of evaporative losses, yet how departures from the idealized flow conditions affect the measured evaporative fluxes via micrometeorological methods remains a subject of debate.

The energy budget method (EBM) remains by far the most common for estimating surface fluxes, and has been widely applied to lakes $[7,4,32]$. The EBM measures the main components of the one-dimensional energy balance equation, namely, the net radiation, the fluxes of heat associated with inflow to and outflow from the water body, and the heat storage change within the lake during the balance period. Then it estimates the two remaining unknown components in the equation, the latent and sensible heat fluxes, by assuming that their ratio, $\beta$, can be defined following Bowen [10]. The basic assumption of the EBM-Bowen ratio approach is that temperature and water vapor have identical turbulent diffusivities $(K)$. This assumption has been shown to be valid under non-advective conditions $[54,16]$, but may not be so under conditions of advection $[58,31,29]$. Formally, advection refers to the state when the mean advective terms $\bar{U} \partial \bar{C} / \partial x+\bar{W} \partial \bar{C} / \partial z$ become a significant contributor to the mean scalar continuity equation, where $\bar{U}$ and $\bar{W}$ are the mean horizontal and vertical velocities, respectively, $\bar{C}$ is the mean scalar concentration of an arbitrary scalar (or temperature), and $x$ and $z$ are the longitudinal and vertical Cartesian coordinates, respectively.

The surface-layer similarity hypothesis, formulated by Monin and Obukhov [35], describes the surface fluxes of mass, heat, and momentum [36,11] using mean scalar gradients in the atmospheric surface layer (ASL) under idealized flow conditions. The introduction of fast-response instruments such as sonic anemometers and IR and UV absorption hygrometers allowed the use of (i) the eddy-correlation flux method [53] for direct measurement of vertical turbulent fluxes that represent the evaporation rates only for idealized flow conditions and (ii) the flux-variance method [56] that relies on Monin-Obukhov similarity theory (MOST) for second-order statistics to estimate surface fluxes based on their respective measured variances. Both direct measurements of latent and sensible heat fluxes using eddy-correlation systems (ECS) were carried out under field conditions over arid land [1,39], agricultural fields $[33,26]$, and lakes [50,5], and flux-variance similarity driven from ECS scalar variance data were used to estimate latent and sensible heat fluxes from different environments $[38,14,1,27,22,3,52]$.

Over the past 3 decades, a number of field studies explored the consequences of horizontal heterogeneity on a number of assumptions invoked in EBM, flux-gradient, and flux-variance methods. Most of these studies primarily focused on dissimilarities between heat and water vapor statistics - including their turbulent diffusivities, their transport efficiencies, and/or their similarity functions $[48,6,19]$. For example, Padro [38] reported different variance similarity functions for water vapor and heat for a wetland, a forest, and a leafless canopy. From measurements above a forest, a grass-covered area and an irrigated field, Katul et al. [27] found that the largest dissimilarity was observed for water vapor data over a forest. Andreas et al. [2] also reported significant dissimilarity in heat and water vapor variance similarity functions even when the horizontal source heterogeneity existed at a $1-\mathrm{m}$ scale. De Bruin et al. [14] found that the latent heat fluxes predicted by the flux-variance method for the plain of La Crau did not correspond to the measured ones. This indicates that over heterogeneous surfaces, the respective efficiencies of heat and water vapor vertical transport may significantly differ - a topic recently explored and extensively reviewed by Lamaud and Irvine [30] including cases inside vegetated canopies.

While it is not our aim here to present a comprehensive review, it is safe to state that earlier observations for nonideal flow conditions revealed the following: (i) the transport efficiencies and eddy diffusivities for heat are often higher than those for water vapor except under low soil moisture or water limiting conditions, and (ii) heterogeneities in ground sources and sinks appear to disproportionately impact flux-variance similarity functions for water vapor when compared to heat. Based on theoretical and observational considerations [26], temperature cannot be treated as a passive scalar, and, as shown by Warhaft [59] and Katul and Hsieh [28], dissimilarities in heat and water vapor statistics need not be strictly connected to departures from idealized flow conditions.

In the vicinity of small lakes or water reservoirs, transitions between a dry and hot microclimate and a cooler and more humid one are likely to impact the application of MOST or EBM to estimate evaporation. Small lakes and reservoirs provide a unique case study here because, unlike vegetated surfaces, there is no biologically induced heterogeneity (e.g. Andreas et al. [2]) generated by stomatal controls on water vapor sources, the heterogeneity has clearly defined geometric boundaries, and the surface roughness is sufficiently low so that the effects of upstream heterogeneities persist over significant downstream distances. The main objective of this study is to explore how the flow statistics of heat and water vapor, most pertinent to lake evaporation measurements, are 'perturbed' from their idealized states (assumed to be well described by MOST scaling) in three water bodies presenting differences in climate, thermal inertia and potentially high advective conditions: Lac Léman in Switzerland, Eshkol reservoir in Israel and Tilopozo wetland in Chile.

\section{Theoretical background}

\subsection{The eddy-correlation method}

For idealized flow conditions, the sensible, $H\left(\mathrm{~W} / \mathrm{m}^{2}\right)$, and latent, $E\left(\mathrm{~W} / \mathrm{m}^{2}\right)$ heat fluxes at the surface can be estimated from turbulent fluxes measured in the atmosphere via: 
$H=C_{p} \rho \overline{w^{\prime} T^{\prime}}$,

$E=L_{e} \rho \overline{w^{\prime} q^{\prime}}$,

where primed quantities indicate turbulent excursions from the time-averaged state (indicated by an over-bar), $C_{p}$ $\left(\mathrm{J} \mathrm{kg}^{-1} \mathrm{~K}^{-1}\right)$ and $\rho\left(\mathrm{kg} \mathrm{m}^{-3}\right)$ are the specific heat capacity at constant pressure and mean density of air, respectively, $L_{e}\left(\mathrm{~J} \mathrm{~kg}^{-1}\right)$ is the latent heat of vaporization of water, $T$ $(\mathrm{K})$ is the air temperature, $w\left(\mathrm{~m} \mathrm{~s}^{-1}\right)$ is the vertical velocity, and $q$ is the specific humidity $\left(\mathrm{kg} \mathrm{kg}^{-1}\right)$. ECS configurations measure $w, T$ and $q$ at high frequency and turbulent fluxes are computed by averaging over intervals ranging from $15 \mathrm{~min}$ to $1 \mathrm{~h}$ (to ensure that stationarity is a reasonable assumption). By choosing appropriate measuring frequencies and averaging time intervals and by applying certain correction procedures (due to sensor misalignment, high frequency losses, sensor separation, etc.), it is possible to obtain accurate values of $H$ and $E$.

\subsection{The energy budget approach}

The general energy budget equation for a water body is given by

$R_{\mathrm{n}}+F_{\text {in }}-F_{\text {out }}-E-H-\Delta S-M=0$,

where $R_{\mathrm{n}}$ is the net radiation, $F_{\text {in }}$ and $F_{\text {out }}$ are the heat fluxes associated with inflow and outflow of water to and from the water body, $E$ and $H$ are, as before, the surface fluxes of latent and sensible heat exchange between the water surface and the atmosphere, $M$ represents the heat fluxes resulting from heat exchanges across the sediments at the bottom of the water body and from biological processes, and $\Delta S$ is the change in the amount of heat stored within the water body during the balance period. Situations in which all components of (3) are accurately known or measured are rare. To simplify (3), $H$ and $E$ are combined using

$\beta=\frac{H}{E}$

with $\beta$ being the Bowen ratio [10]. This $\beta$ can be estimated by relating the turbulent fluxes to their mean gradients using a gradient-diffusion approximation with the corresponding eddy diffusivity, $K$. For open water surfaces, where the mean vapor pressure at the surface, $\overline{e_{\mathrm{s}}}$, can be assumed to be at saturation at the mean surface temperature, $\overline{T_{\mathrm{s}}}, \beta$ is defined as

$\beta=\frac{p}{0.622} \frac{C_{p}}{L_{e}} \frac{K_{T}}{K_{q}} \frac{\left(\overline{T_{\mathrm{s}}}-\overline{T_{\mathrm{a}}}\right)}{\left(\overline{e_{\mathrm{s}}}-\overline{e_{\mathrm{a}}}\right)}$,

where $p$ is the atmospheric pressure, $\overline{T_{\mathrm{a}}}$ and $\overline{e_{\mathrm{a}}}$ are the mean temperature and vapor pressure in the air, respectively, at some reference level, and $K_{T}$ and $K_{q}$ are the heat and vapor diffusivities. From similarity theory, it is generally assumed that $\frac{K_{T}}{K_{a}}=1[43,19]$, which allows a relatively simple estimate of $\beta$, even though this assumption may not be valid under unstable $[44,59]$ and advective conditions $[58,31,15]$.

\subsection{Monin-Obukhov similarity theory for scalar variances}

For idealized flow conditions, the scaled standard deviation of an atmospheric variable $C, \sigma_{c} / C^{*}$ is a function of the dimensionless stability parameter $(z / L)$, where $z$ is the measurement level (above the zero-plane displacement in case of vegetated surfaces), and $L$ is the Obukhov length. Hence,

$\frac{\sigma_{c}}{\left|C^{*}\right|}=f\left(-\frac{z}{L}\right)$,

where $\sigma_{c}$ is the standard deviation of a scalar entity $C$, and $C^{*}$ is a concentration scale defined as $C^{*}=\frac{\overline{w^{\prime} C^{\prime}}}{u_{*}}$, with $w^{\prime}$ and $c^{\prime}$, as before, being turbulent fluctuations of $w$ and $C$ about their mean value, and $u_{*}$ is the friction velocity.

Under free convection conditions, simple expressions for $\sigma_{w}$, the standard deviation of $w$, as a function of $(-z / L)$ can be derived by assuming independence on $u_{*}$

$\frac{\sigma_{w}}{u_{*}}=C_{w}\left(-\frac{z}{L}\right)^{1 / 3}$,

with $C_{w}$ being approximately equal to $1.8[60,23,12]$. For $T$, a similar relationship was suggested by Kader and Yaglom [23] for $\sigma_{T}$ at the convective limit,

$\frac{\sigma_{T}}{\left|T^{*}\right|}=C_{T}\left(-\frac{z}{L}\right)^{-1 / 3} ; \quad T^{*}=\frac{\overline{w^{\prime} T^{\prime}}}{u_{*}}$,

with $C_{T}=0.95$ for $(-z / L)>0.04$. In fact, several field experiments conducted in different environments have shown that the value of this similarity constant is practically invariant ( $\left.C_{T} \sim 0.92-0.99[60,49,23,1,3]\right)$, and is often labeled 'universal' $[40,1]$. For $q$, Högström and SmedmanHögström [20] have shown a similar functional relationship:

$\frac{\sigma_{q}}{\left|Q^{*}\right|}=C_{q}\left(-\frac{z}{L}\right)^{-1 / 3} ; \quad Q^{*}=\frac{\overline{w^{\prime} q^{\prime}}}{u_{*}}$

In their experiment, the value of $C_{q}$ was equal to 1.04 for $(-z / L)>0.1$, a value that is higher than $C_{T}$. It was shown in several studies that the values for $C_{q}$ were actually much larger than $C_{T}\left(C_{q} \sim 1.1-1.5[37,13,27,3,61]\right)$ already indicating that $\sigma_{q}$ and $\sigma_{T}$ may behave differently. For unstable conditions, this was one reason why the transport of heat appears more efficient than that of water vapor $[26,27,3]$. Katul and Hsieh [28] demonstrated that $C_{T}$ must be smaller than $C_{q}$ even for idealized conditions - mainly because of the active role of temperature in the production of turbulent kinetic energy. Roughly, the active role of temperature may explain why $C_{q}$ exceeds $C_{T}$ by some $10-25 \%$.

The $\beta$ in (4) can be derived from the fluxes in (1) and (2):

$\beta=\frac{C_{p}}{L_{e}} \frac{\overline{w^{\prime} T^{\prime}}}{\overline{w^{\prime} q^{\prime}}}$

where all the parameters and variables maintain their previous definitions. The transport efficiencies for temperature, $R_{w T}$ and for humidity, $R_{w q}$, are defined as 
$R_{w T}=\frac{\overline{w^{\prime} T^{\prime}}}{\sigma_{w} \sigma_{T}} ; \quad R_{w q}=\frac{\overline{w^{\prime} q^{\prime}}}{\sigma_{w} \sigma_{q}}$.

Consequently, $\beta$ in (10) can be expressed in terms of $R_{w T}$ and $R_{w q}$ and the ratio of scalar variances (rather than their gradients) to give

$\beta=\frac{C_{p}}{L_{e}} \frac{\left|R_{w T}\right|}{\left|R_{w q}\right|} \frac{\sigma_{T}}{\sigma_{q}}$.

Following MOST ((8) and (9)), $\beta$ can also be estimated from $\sigma_{T}$ and $\sigma_{q}$ using:

$\beta=\frac{C_{p}}{L_{e}} \frac{C_{q}}{C_{T}} \frac{\sigma_{T}}{\sigma_{q}}$.

Consequently, $\frac{C_{q}}{C_{T}}=\frac{\mid R_{w} T}{\left|R_{w q}\right|}[3,30]$ and the ratio of $C_{T}$ to $C_{q}$ is directly linked to the transport efficiencies. Dissimilarity in transport efficiencies of $T$ and $q$ should necessarily reflect inequality between $C_{T}$ and $C_{q}$. Finally, to establish relationships between flux-profile and flux-variance similarity functions, we consider the different expressions for $\beta$ presented above ((5), (12) and (13)) to derive the following relationship:

$\frac{\sigma_{T}}{\sigma_{q}}=\frac{p}{0.622} \frac{C_{T}}{C_{q}} \frac{K_{T}}{K_{q}} \frac{\left|\left(\overline{T_{\mathrm{s}}}-\overline{T_{\mathrm{a}}}\right)\right|}{\left|\left(\overline{e_{\mathrm{s}}}-\overline{e_{\mathrm{a}}}\right)\right|}$.

Similarity theory (in its gradient and variance forms) assumes that $\frac{C_{q}}{C_{T}}=\frac{K_{T}}{K_{q}}=1$, so that

$\frac{\sigma_{T}}{\sigma_{q}}=\frac{p}{0.622} \frac{\left|\left(\overline{T_{\mathrm{s}}}-\overline{T_{\mathrm{a}}}\right)\right|}{\left|\left(\overline{e_{\mathrm{s}}}-\overline{e_{\mathrm{a}}}\right)\right|}$.

Departure from this proportionality between variances and differences with height of $T$ and $e$ (15) can indicate situations in which the ratio between transport efficiencies or diffusivities of heat and water vapor differ from unity (i.e. deviate from the similarity theory) without requiring any velocity statistics measurements.

It was shown by Albertson et al. [1] and Parlange et al. [42] that $H$ can be estimated relatively accurately from the free convective second-moment model based on $\sigma_{T}$ and $T_{\mathrm{a}}$ data using

$H=C_{T}^{-3 / 2} \sigma_{T}^{3 / 2} T_{\mathrm{a}}^{-1 / 2} \rho C_{p}(k g z)^{1 / 2}$

where $k$ is the von Karman constant and $g$ is gravitational acceleration, even when conditions are not purely free-convective. Consequently, following the Bowen ratio definition (4), and using appropriate expressions for $\beta$ ((5) or (13)), it is possible to estimate $E$. The $E$ estimates are of lower accuracy than those of $H$, because of uncertainties in $K_{T} / K_{q}(5)$ or $C_{T} / C_{q}(13)$.

\section{Instruments and methods}

\subsection{Site descriptions}

Three water bodies situated in different climatic zones and representing large variations in surface area and volume were considered. These sites include the Eshkol reser- voir in Israel, the Tilopozo wetland in Chile, and Lac Léman in Switzerland (see Fig. 1).

\subsubsection{The Eshkol reservoir}

The Eshkol reservoir is located in the Bet-Netofa valley in northern Israel $\left(32^{\circ} 46^{\prime} \mathrm{N} ; 35^{\circ} 14^{\prime} \mathrm{E}, 145\right.$ m.a.s.l), and is characterized by a Mediterranean climate. The reservoir is part of the National Water Carrier, and is operated by Mekorot, the Israel National Water Company. It is a settling reservoir that receives water intermittently, by gravity flow in an open channel, from another upstream reservoir of the same system. Eshkol is a square reservoir with $600 \mathrm{~m}$ sides and an average depth of $3.5 \mathrm{~m}$. Water flows out of this reservoir into an adjacent operational, but much larger reservoir, at the same site. Being a settling reservoir, it is kept at an almost constant water level. Measurements were conducted during summer of 2005. Data from days of year (DOY) 245-252 (September 2-9) were considered.

The measurements were conducted on a platform at the center of the reservoir (Fig. 1 - upper). The platform was at $0.75 \mathrm{~m}$ above the water level and was constructed of a $2.2 \mathrm{~m} \times 2.2 \mathrm{~m}$ steel screened floor on a concrete frame. The platform allowed a minimum fetch of $300 \mathrm{~m}$ in all wind directions. The ECS consisted of a three-dimensional sonic anemometer (model 81000, R.M. Young, USA) and a krypton hygrometer (model KH20, Campbell Sci., USA). The sensor height was $2.4 \mathrm{~m}$ above the water surface level. To minimize wind distortion, eddy covariance sensors were deployed on an arm extending about $2.5 \mathrm{~m}$ away from the platform structure towards the north-west, the direction of prevailing wind. Sampling frequencies and averaging intervals were $10 \mathrm{~Hz}$ and $15 \mathrm{~min}$, respectively. ECS raw data were corrected using the procedures suggested by Horst [21] and Tanner and Greene [55]. Oxygen corrections for $q$ and $\sigma_{q}$ were done as recommended in Van Dijk et al. [57]. The three-dimensional sonic anemometer was also used to collect high frequency wind data for analysis of turbulence characteristics. Sonic temperature was converted to kinetic temperature (using the measured air humidity) and was used for sensible heat flux measurements. Net radiation was measured by a net radiometer (Q*7.1, REBS, USA) installed $1 \mathrm{~m}$ above the water surface level, mounted on an arm extending about $2 \mathrm{~m}$ from the platform. Global radiation was measured by a pyranometer (CM10, Kipp and Zonen, The Netherland) installed at $3 \mathrm{~m}$ height. Dry and wet bulb air temperatures were measured by two aspirating psychrometers, shielded against direct solar radiation, and positioned at heights of 0.9 and $2.9 \mathrm{~m}$ above the water surface level. Vertical profile of water temperature was measured at $0.5 \mathrm{~m}$ intervals near the platform by seven insulated thermocouples (T-type; sampling frequencies and averaging intervals were $0.2 \mathrm{~Hz}$ and $15 \mathrm{~min}$, respectively).

\subsubsection{The Tilopozo wetland}

The Tilopozo wetland is located in the hyper-arid Atacama Desert in northern Chile at an elevation of $2320 \mathrm{~m}$. 

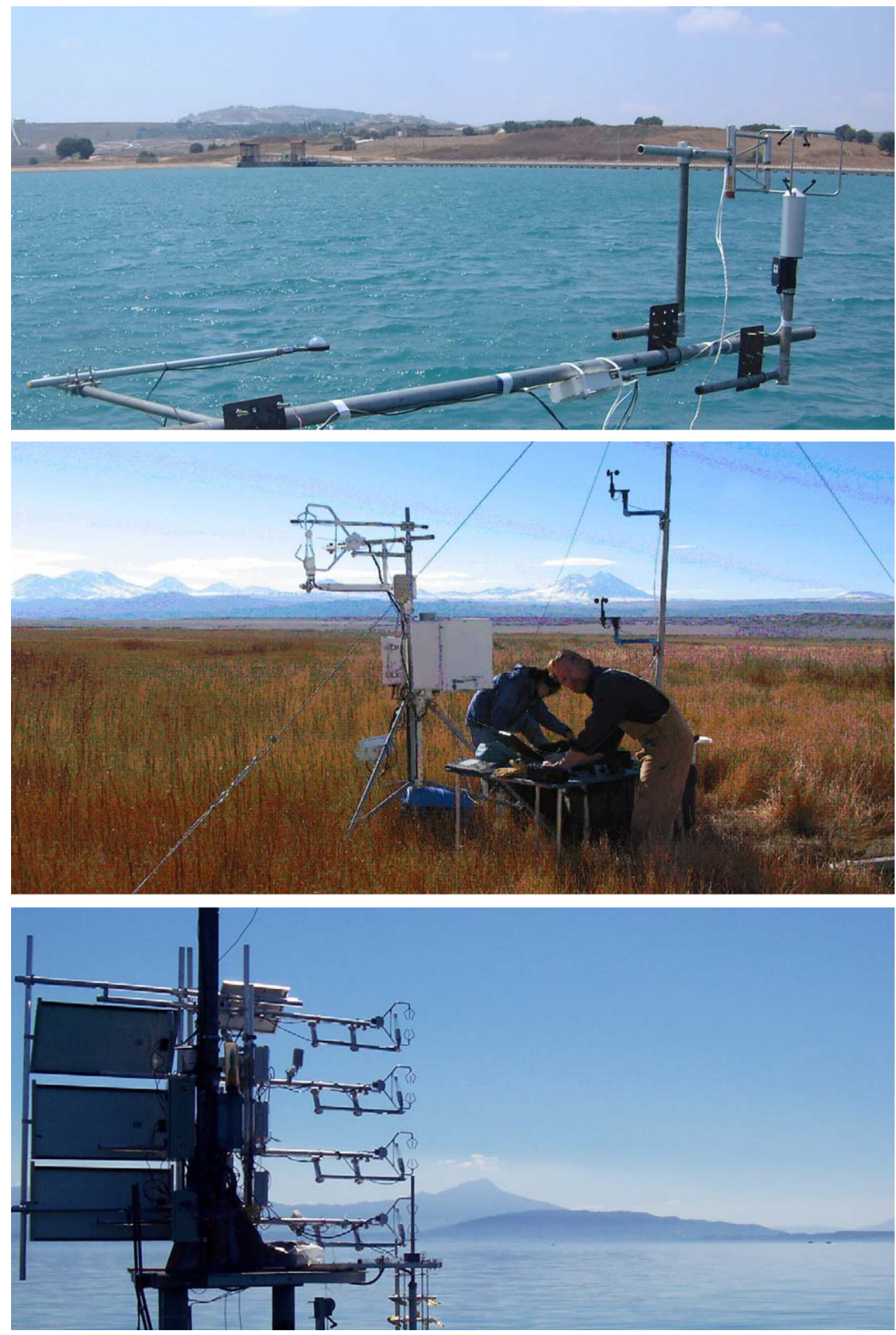

Fig. 1. Pictures from the three sites, illustrating the three different environments and experimental set-ups: Eshkol reservoir; Israel (upper); Tilopozo wetland, Chile (center); Lac Léman, Switzerland (lower). In the wetland, a 1-D sonic anemometer and a Krypton hygrometer were installed most of the time.

The wetland is located at the southern end of the Salar de Atacama $\left(23^{\circ} 47^{\prime} 00.8^{\prime \prime} \mathrm{S} ; 068^{\circ} 14^{\prime} 13.9^{\prime \prime} \mathrm{W}\right)$ and consists of a complex of springs, ponds, wetlands and phreatophyte vegetation within an area of approximately 600 ha. The climate of the region can be considered hyperarid, with precipitation of less than $20 \mathrm{~mm} / \mathrm{yr}$ [45] that rarely occurs from convective systems during the austral summer. Mean daily summer temperatures are approximately $22^{\circ} \mathrm{C}$ with winter (July) daily mean of $\sim 8^{\circ} \mathrm{C}$ [24]. Large daily temperature swings are common. 
In spite of the hyperaridity of the Atacama Desert, the wetland serves as the major ground water discharge zone for the Monturaqui-Negrillar-Tilopozo aquifer complex draining the high Andes region. The wetland is supported exclusively by ground water discharge. The Tilopozo wetland varies greatly in landscape types, depth of water, vegetation and soil types. It consists of salt crust and bare soil areas, open water bodies, flooded vegetation and vegetated grassland areas. Ground water discharges both as discrete springs as well as diffusely in wetland areas, and zones of shallow groundwater support a variety of phreatophytes. The salinity of water found in the wetland is highly variable, but generally progresses from $<1000 \mu \mathrm{S} / \mathrm{cm}$ in the upstream areas of the wetland to halite saturation at the most downstream lagoons. The total springtime discharge from the area is estimated to range from 514 to $12591 \mathrm{~s}^{-1}$ [34].

In the winter of 2002 (July 14-24; DOY 195-205), an ECS tower was installed in the central portion of the Tilopozo wetland to provide preliminary estimates of winter season evapotranspiration (Fig. 1 - center). The site was chosen to be representative of flooded wetland vegetation in a saturated soil situation. The flux tower consisted of a one-dimensional sonic anemometer (Campbell Scientific CA27), fine wire thermocouple, an open-path Krypton hygrometer (Campbell Scientific KH20) and net radiometer (REBS Q7.1). The fast-response sensors were installed at a height of $2 \mathrm{~m}$ above the land surface. Also installed at this station were instruments to measure soil temperature, soil heat flux, air temperature, humidity, and horizontal wind speed and direction. Soil heat flux could not be accurately calculated from the measured data as only one soil depth was monitored for temperature and the presence of dense senescent vegetation may have significantly damped much of the soil heat flux. It was also observed that surface flows of water traversed the site, further making the measurements from soil heat flux plates and soil temperature of questionable validity. Fluctuations in vertical wind velocity, vapor density and temperature were measured at $10 \mathrm{~Hz}$, with temporal averaging conducted at 15-min intervals. Standard corrections for oxygen and buoyancy were made either during data collection or during post processing (see [24] for a summary of primary data processing).

The vegetation directly surrounding the measurement site is tall grass (Fig. 1 - center) and the zero-plane of displacement, $d$, was estimated such that $z=(Z-d)=1.5 \mathrm{~m}$. This vegetation was senescent during the measurement period due to the wintertime conditions, but still was very dense and appeared to have provided a very efficient surface mulch to reduce evaporation from the surface. The soil near the surface was both clay and organic matter rich, with standing water present within the plant canopy.

This site was chosen because it is located in an area with a fairly homogenous fetch of vegetation and very shallow water table. Vegetation and presence of water at the land surface were found to be consistent for several hundred meters upwind of the flux tower, and data are only reported for times when wind conditions were optimal for measuring from this uniform fetch.

\subsubsection{Lac Léman}

The measurements over Lac Léman (Lake Geneva) in Switzerland were collected on a 10-m high tower, $100 \mathrm{~m}$ away from the northern shore of the lake. The tower is exposed to a $30 \mathrm{~km}$ wind fetch from the south and west directions. The lake, the largest in Switzerland, is part of the Rhone River that starts in the Alps, flows through the lake, meets the Saône River near Lyon, turns south, and eventually flows into the Mediterranean Sea. The annually averaged discharge rate of the lake is over $500 \mathrm{~m}^{3} \mathrm{~s}^{-1}$. The climate around the lake is relatively temperate with high precipitation rates and increased river and lake flows during the spring snowmelt season. The lake lies between the Alps and the Jura mountain chains (sources of water and snowmelt for the lake) and between Switzerland (from the north, east, and west) and France (from the south). Wind regimes and weather patterns in the area are strongly influenced by the orography. The measurement campaign lasted from mid August until late October of 2006 (DOY 226-298). Four 3-dimensional sonic anemometers (Campbell Scientific CSAT3) and four open path gas analyzers (Licor-7500) measured wind speed, temperature, and humidity at $20 \mathrm{~Hz}$. The four pairs were setup as a vertical array oriented towards the southwest and mounted at the following heights above the water surface: $1.65 \mathrm{~m}, 2.30 \mathrm{~m}, 2.95 \mathrm{~m}$ and $3.60 \mathrm{~m}$ (Fig. 1 - lower). Additional supporting measurements included net radiation (Kipp and Zonen NR-Lite), water surface temperature (thermocouples), air relative humidity and temperature (Rotronic hygroclip S3), surface wave height and speed (Pressure systems Inc. submersible level transducer model $735 ; 0.05 \%$ accuracy of full scale), as well as several point-measurements of air and water temperature.

Only data with wind coming from the south and southwest were used to ensure that the minimum fetch was not less than $10 \mathrm{~km}$ and that the tower did not influence the measurements. Assuming that the internal equilibrium layer height is roughly equal to $1 / 100$ of the downstream distance $[41,42,12,8,9]$, a fetch of $10 \mathrm{~km}$ ensures that the measurements are fully within this internal equilibrium layer. In practice, the growth of the water vapor internal boundary layer may be obtained with a scanning Raman Lidar $[17,18,42]$.

The lake water beneath the measuring station was only $3 \mathrm{~m}$ deep and turbulence in the water, if present at all, was weak and intermittent. This suggests that the interaction between the air and lake was mainly influenced by the atmospheric dynamics rather than the lake dynamics. The raw data was collected at $20 \mathrm{~Hz}$ using a Campbell Scientific CR5000 data logger and all computations were done afterwards. For the EC flux calculations, pre-processing and data conditioning mainly included triple rotation to correct the yaw, pitch, and roll misalignments of the sonic anemometers, linear detrending, and the Webb correction. 


\subsection{Data processing}

Data collection and instruments used at each of the three sites were essentially similar; hence, we describe the main data processing procedures and highlight any sitespecific adjustments made. High frequency variations in temperature and humidity were measured in the wetland by fine wire thermocouples (for $\sigma_{T}$ ) and the Krypton hygrometer (for $\sigma_{q}$ ). For the lake and reservoir, $\sigma_{T}$ was computed from the temperature measurements of the sonic anemometers (corrected for moisture content of the air) while $\sigma_{q}$ was computed from the data of the LICOR gas analyzer for the lake and a Krypton hygrometer for the reservoir. Means and standard deviations of temperature, hygrometer output $\left(\rho_{v}\right)$ and $\ln \left(\rho_{v}\right)$ were calculated on 15 min intervals from the raw 10 (or 20) $\mathrm{Hz}$ data and the values of $q$ calculated accordingly. The value of $u_{*}$ was calculated as $u_{*}=\overline{-\left(u^{\prime} w^{\prime}\right)^{0.5}}$ for the lake and $u_{*}=\left(\overline{\left(u^{\prime} w^{\prime}\right.}\right)^{2}+\left(\overline{\left.v^{\prime} w^{\prime}\right)^{2}}\right)^{1 / 4}[51]$ for the reservoir, with $u$ and $v$ being the two horizontal wind components. In the case of the Tilopozo wetland, where direct $u_{*}$ data were not available, the friction velocity was deduced from 15-min mean horizontal wind speed and estimates of surface roughness. Scaling of the standard deviations by $T^{*}$ and $Q^{*}\left((8)\right.$ and (9)) used the calculated $u_{*}$ and the calculated sensible and latent heat fluxes, respectively. Finally, the Monin-Obukhov length scale, $L$, was calculated using the following relationship:

$L=\frac{-\rho u_{*}^{3}}{k g\left(\frac{H}{C_{p} T_{\mathrm{a}}}+0.61 \frac{E}{L_{e}}\right)}$.

Sensible and latent heat fluxes were estimated using (1) and (2), and the measured Bowen ratio, $\beta$, was estimated using (4).

\section{Results and discussion}

\subsection{Environmental characteristics of the three sites}

The fluxes and environmental characteristics measured at the three sites are presented in Figs. 2 and 3 in terms of ensemble mean and standard deviations of diurnal curves for the respective measurement periods. The main fluxes of the energy budget, net radiation, $R_{\mathrm{n}}$, and latent and sensible heat fluxes, $E$ and $H\left(\mathrm{~W} \mathrm{~m}^{-2}\right)$ are depicted in Fig. 2a-c. Fig. 3a-c presents the horizontal wind speed, $U_{\mathrm{h}}\left(\mathrm{m} \mathrm{s}^{-1}\right)$ for the three sites, the vertical temperature difference, $\left(T_{\mathrm{a}}-T_{\mathrm{s}}\right)\left({ }^{\circ} \mathrm{C}\right)$ for the lake and the reservoir, where $T_{\mathrm{s}}$ is the water surface temperature, and $T_{\mathrm{a}}$ and $T_{\mathrm{ss}}$ separately for the wetland, as $T_{\mathrm{ss}}$ was measured several centimeters below both the saturated soil surface and the dense senescent vegetation and is unlikely to represent the true surface temperature as $T_{\mathrm{s}}$ does. For the lake, only data collected for DOY 261-266 are depicted. Net radiation was highest for the reservoir, about $750 \mathrm{~W} \mathrm{~m}^{-2}$, and was lower and of similar magnitude at the lake and the wetland. The
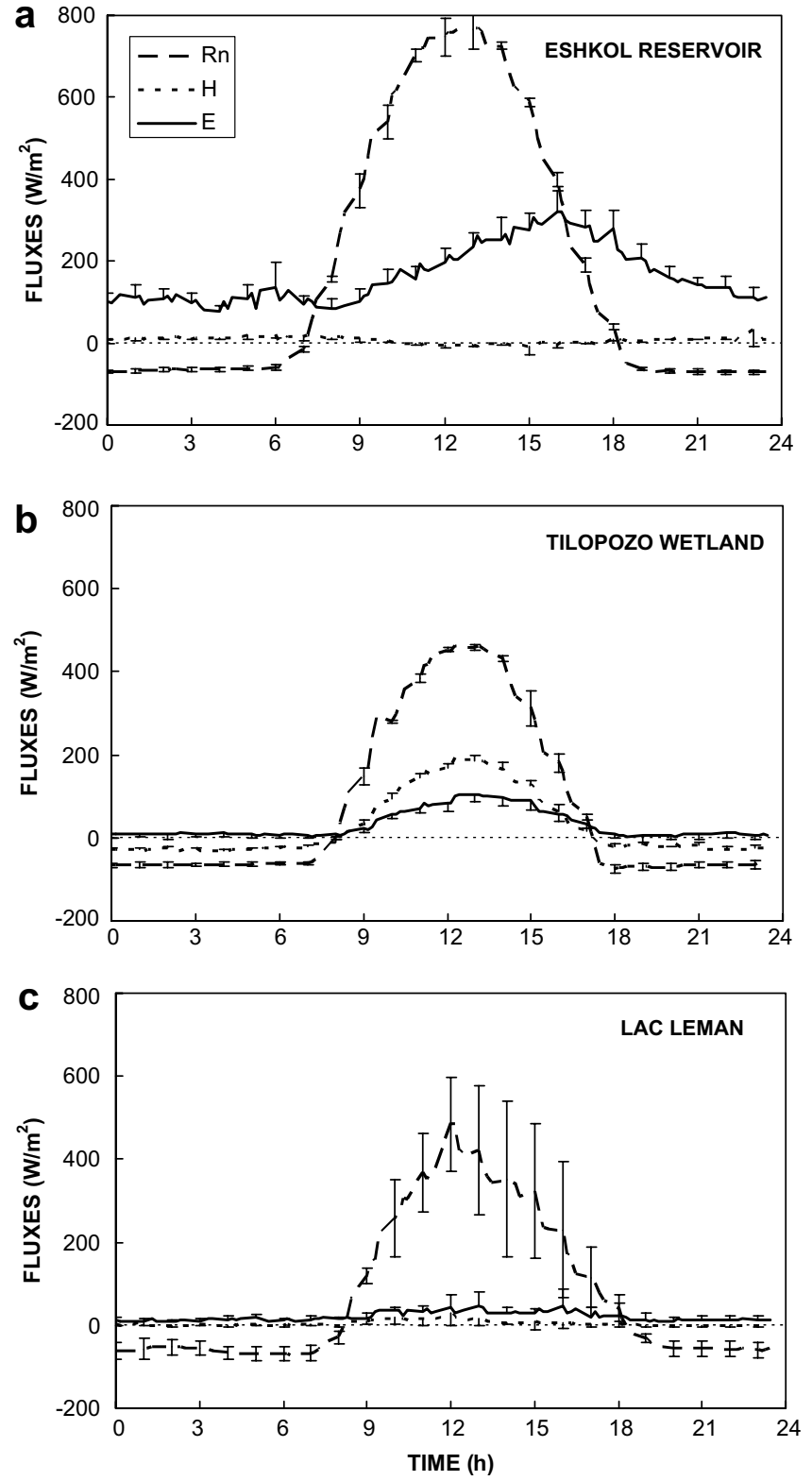

Fig. 2. Mean and standard deviations (shown as error bars) of net radiation, $R_{\mathrm{n}}$, latent heat flux, $E$, and sensible heat flux, $H$, expressed in $\left[\mathrm{W} \mathrm{m}^{-2}\right]$, for the respective measurement periods at the three sites: (a) Eshkol reservoir; (b) Tilopozo wetland; (c) Lac Léman. The thin dashed line represents the zero-flux line.

lower net radiation was mainly due to clouds for the lake (notice the high standard deviations during daytime), and due to the presence of vegetation (with higher albedo than water) as well as the low declination angle during the austral winter for the wetland. Consequently, when the high net radiation was combined with the strong afternoon sea-breeze (see Fig. 3), it is not surprising that $E$ was highest for the reservoir. Note that the diurnal course of $E$ from the reservoir was not in phase with the net radiation and appears to be more correlated with the diurnal variation of mean wind $\left(U_{\mathrm{h}}\right)$ (Fig. 3a), suggesting that advection is clearly significant. The lowest $E$ peak was measured for 

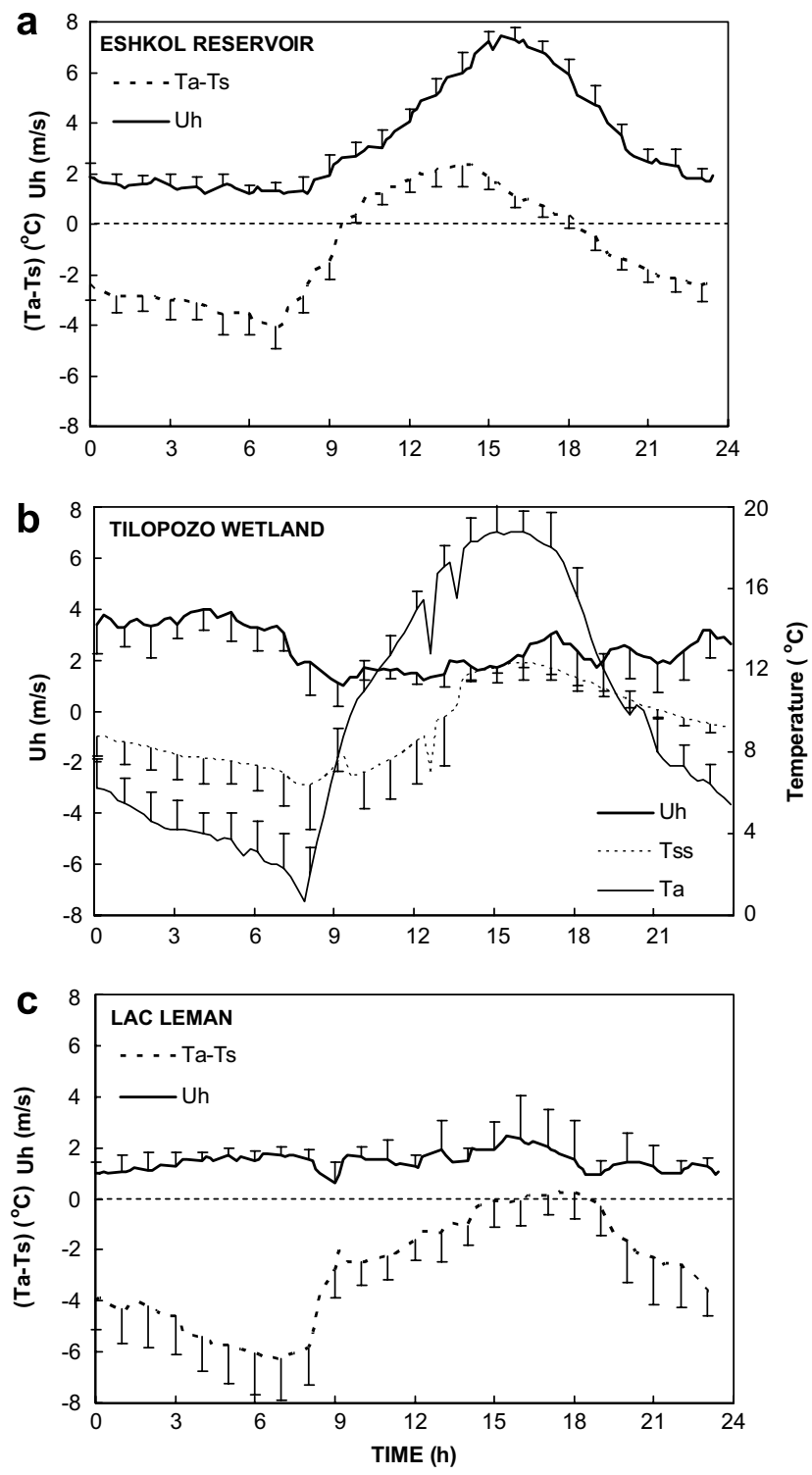

Fig. 3. Mean and standard deviations of horizontal wind speed, $U_{\mathrm{h}}$ $\left[\mathrm{m} \mathrm{s}^{-1}\right]$, and vertical temperature difference, $\left[T_{\mathrm{a}}-T_{\mathrm{s}}\right]\left({ }^{\circ} \mathrm{C}\right)$, for the respective measurement periods at the three sites: (a) Eshkol reservoir; (b) Tilopozo wetland; (c) Lac Léman. For the wetland, air temperature, $T_{\mathrm{a}}$, and soil surface temperature, $T_{\mathrm{ss}}$, are presented separately.

the lake. The relatively high positive $E$ rates at night at all the three sites are related to the negative $\left(T_{\mathrm{a}}-T_{\mathrm{s}}\right)$ values (Fig. 3).

Differences in thermal inertia among the three systems are most evident in the sensible heat flux. For the reservoir, $H$ was slightly positive at night and became negative in the afternoon (Fig. 2a) - concomitant with the sign of $\left(T_{\mathrm{a}}-T_{\mathrm{s}}\right)$. For the lake, it was also slightly positive at night but remained positive while increasing during daytime (Fig. 2c). However, for the wetland (Fig. 2b), it was negative at night but became positive during the day, being larger than $E$ around noon. At that site, $T_{\text {a }}$ was significantly higher than $T_{\mathrm{ss}}$ around noon, but the strong winds occurred at night (Fig. 3b). In contrast to typical terrestrial systems, the 2-m air temperature $T_{\mathrm{a}}$ was usually higher than soil temperature during times of positive (upward) sensible heat flux at the Tilopozo wetland. The observed soil temperature showed only a muted response to air temperature and consistently lagged behind the daily air temperature rise. The dense vegetation appears to have served as an efficient surface mulch, isolating much of the underlying saturated soil from significant heat transfer. Therefore, the positive sensible heat flux observed at the wetland is likely to be driven by warming of the dense senescent vegetation whose temperature was not measured during the experimental period.

The trends presented above indicate significant differences in conditions that determine heat and vapor exchanges with the atmosphere. Two variables that play a major role in these exchanges are the temperature and humidity gradients above the water surface, $\Delta T / \Delta z$ and $\Delta q / \Delta z$, respectively. Considering the specific experimental set-up in each site, these gradients are approximated by $\frac{\Delta T}{\Delta Z}=\frac{\left(T_{\mathrm{a}}-T_{\mathrm{s}}\right)}{Z}$ and $\frac{\Delta q}{\Delta Z}=\frac{\left(q_{\mathrm{a}}-q_{\mathrm{s}}\right)}{Z}$, where $q_{\mathrm{s}}$ is the saturation specific humidity computed at the temperature of the water surface, $T_{\mathrm{s}}$, and $q_{\mathrm{a}}$ and $T_{\mathrm{a}}$ are the specific humidity and the temperature of the air at height $z$ above the water surface. These gradients are strongly affected by advective conditions at the site, including incoming air or inflow and outflow of water, especially in the reservoir because of its small volume and fast turnover rate. These gradients were calculated for the three sites and $\Delta q / \Delta z$ is plotted against $\Delta T / \Delta z$ to compare between the respective conditions at each site (Fig. 4a). For the wetland, only the gradients measured at night-time (between 22.00 and 5.00), for which $T_{\mathrm{ss}}$ is assumed to better approximate the water surface temperature, are depicted. This summary of the data demonstrates that each site is characterized by a unique relationship between the two gradients.

For the wetland, a large variation in the $T$ gradient was observed, and a wide range of both positive and negative values was recorded, between $-4{ }^{\circ} \mathrm{C} \mathrm{m}^{-1}$ and $2{ }^{\circ} \mathrm{C} \mathrm{m}^{-1}$. Following the definition of the $T$ gradient, negative values indicate unstable stratification conditions. Therefore, conditions of strong instability, mainly induced by the temperature profile, often prevailed in the wetland at night (see also Fig. 3b) though, as earlier stated, this gradient and its linkage with the local heat flux should be interpreted with caution given the insulating role of the vegetation. The gradient in $q$ remained relatively small, between $-0.004 \mathrm{~m}^{-1}$ and $-0.002 \mathrm{~m}^{-1}$. Although the Tilopozo site is located in a hyperarid region, the large extent of the wet surfaces of the wetland reduced heterogeneity in humidity and significantly increased the specific humidity in the overlying atmosphere at the flux site.

For the reservoir, relatively large positive gradients in $T$ were observed, and these varied from -1.0 to $7.0^{\circ} \mathrm{C} \mathrm{m}^{-1}$. A sharp power-like increase of the gradients in $q$ is associated with the variation of the $T$ gradients. This can be associated with a potential for high advective conditions at that site, when incoming hot and dry air at relatively high veloc- 

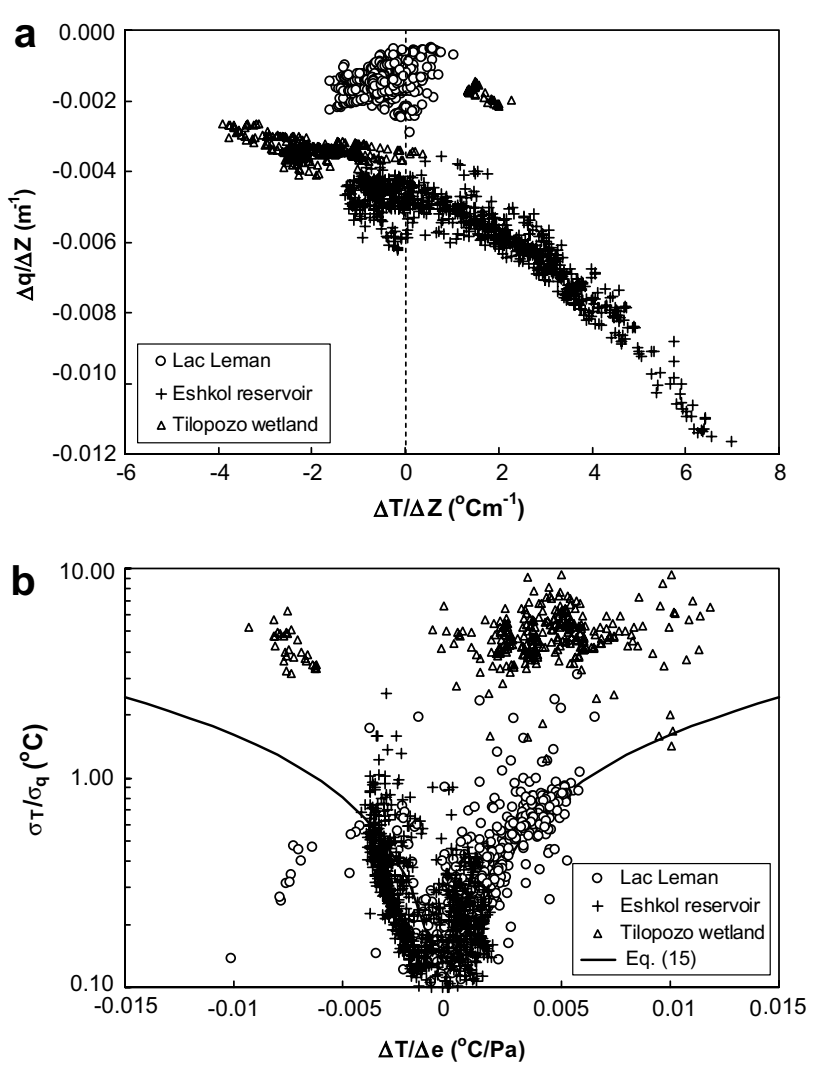

Fig. 4. Comparison between temperature and humidity regimes at the three sites: (a) specific humidity gradient $\Delta q / \Delta z\left[\mathrm{~m}^{-1}\right]$ versus temperature gradient $\Delta T / \Delta z\left[{ }^{\circ} \mathrm{C} \mathrm{m}^{-1}\right]$; (b) the measured relationship between $\frac{\sigma_{T}}{\sigma_{q}}$ and $\frac{\left(\overline{T_{\mathrm{s}}}-\overline{T_{\mathrm{a}}}\right)}{\left(\overline{\bar{e}_{\mathrm{s}}}-\overline{\bar{e}_{\mathrm{a}}}\right)}$ and the corresponding expression in (15) (solid line). For the wetland, only night-time data are depicted.

ities in the afternoon caused an increase in latent heat fluxes (Figs. 2a and 3a). This trend in the relationship between gradients in $T$ and $q$ seems to fit also the wetland data that correspond to stronger wind and colder air at night (Fig. 3b).

The differences between the environments are also reflected in differences between the measured and the computed mean $\beta$ values ((4) and (5)). For the lake, the mean measured $\beta$ value was 0.26 (with a standard deviation of 0.24 ) while the computed one was 0.28 (stdev of 0.19 ). For the reservoir, the mean measured $\beta$ value was 0.079 (stdev of 0.125 ) while the computed one was 0.093 (stdev of 0.11 ). These respective differences between measured and computed values illustrate to what extent the $E$ estimates based on the energy budget method (with the Bowen assumption) are influenced by departures from the idealized flow state.

Again, because of the high uncertainty in the gradient measurements at the three sites, we use these only qualitatively to contrast the three systems rather than in actual flux-gradient or eddy-diffusivity calculations. As earlier demonstrated a unique proportionality between $\frac{\sigma_{T}}{\sigma_{q}}$ and $\frac{\left(\overline{T_{\mathrm{s}}}-\overline{T_{\mathrm{a}}}\right)}{\left(\overline{e_{\mathrm{s}}} \overline{\bar{e}_{\mathrm{a}}}\right)}$ exists from idealized flow conditions (15). This relationship is shown for the three sites and the respective experimental periods in Fig. 4b. Most of the data for the lake and the reservoir are in general agreement with (15), as depicted by the solid curve. However, night-time data for the wetland are far from following the trend suggested in (15) due to the insulating role of the vegetation.

\subsection{Monin-Obukhov similarity approach}

As earlier stated, Monin-Obukhov similarity functions may be used as a reference model for idealized flow states, and anomalous behavior from these reference functions can be used to 'finger-print' the effects of advection on these scaling functions. The flux-variance relationships in particular have already been shown to be sensitive to 'non-ideal' flow states given the sensitivity of the variances to any 'added' source of heterogeneity beyond what is produced by the local flux.

The scaled standard deviations of the measured fluctuations in vertical wind velocity, $\sigma_{w} / u^{*}$, temperature, $\sigma_{T} / T^{*}$, and water vapor, $\sigma_{q} / Q^{*}$, versus the dimensionless stability parameter $(-z / L)$ are depicted in Fig. $5 \mathrm{a}-\mathrm{c}$ for the three sites. The $\sigma_{w} / u^{*}$ versus $(-z / L)$ relationships are similar (Fig. 5a) across sites and do not diverge significantly from functions derived for idealized flow conditions except at very low values of $-z / L$ where the free convection scaling leading to the $\pm 1 / 3$ powers in (7)-(9) is no longer valid. This convergence indicates that the measured vertical transfer of momentum is not significantly affected by advection or other non-uniformities at all three sites. The data are also well represented by (7) with the $C_{w}=1.8$, as suggested by Brutsaert [12]. The equation suggested by De Bruin et al. [14] (not shown) was also found to fit the data quite well.

The $\sigma_{T} / T^{*}$ versus $(-z / L)$ relationships (Fig. $5 \mathrm{~b}$ ) are also similar for all the three sites though much larger scatter is evident. The curve corresponding to (8) with $C_{T}=0.95$, the value found to correspond to a wide variety of land surfaces $[1,40]$, represents the lower boundary of all the measured values, as has been reported by other studies.

The $\sigma_{q} / Q^{*}$ versus $(-z / L)$ relationships were similar for all the sites (Fig. 5c). The scatter appears reduced when compared to the scaled temperature variance, and the data for the reservoir are generally lower than those for the lake and the wetland. The curve corresponding to (9) with $C_{q}=1.3$, a value in the middle of the range found in various studies (see Section 2.3), corresponds to the measured values for $(-z / L)>0.1$. The higher value of $C_{q}$ compared to $C_{T}$ that corresponds to the plotted curves (Fig. 5b and c) is in agreement with several experiments $[13,27,3]$, and with the analysis of Katul and Hsieh [28] that partially explained why $C_{q}$ should be larger than $C_{T}$ (though their analysis is strictly based on the active role of temperature).

Inherent to the Bowen ratio approach or to the flux-variance method are the assumptions that the heat and vapor diffusivities, $K_{T}$ and $K_{q}$, or the transport efficiencies for temperature and humidity, $R_{w T}$ and $R_{w q}$, are respectively equal. These properties can be estimated from the available measured data ((5) and (11)). Because we do not have redun- 

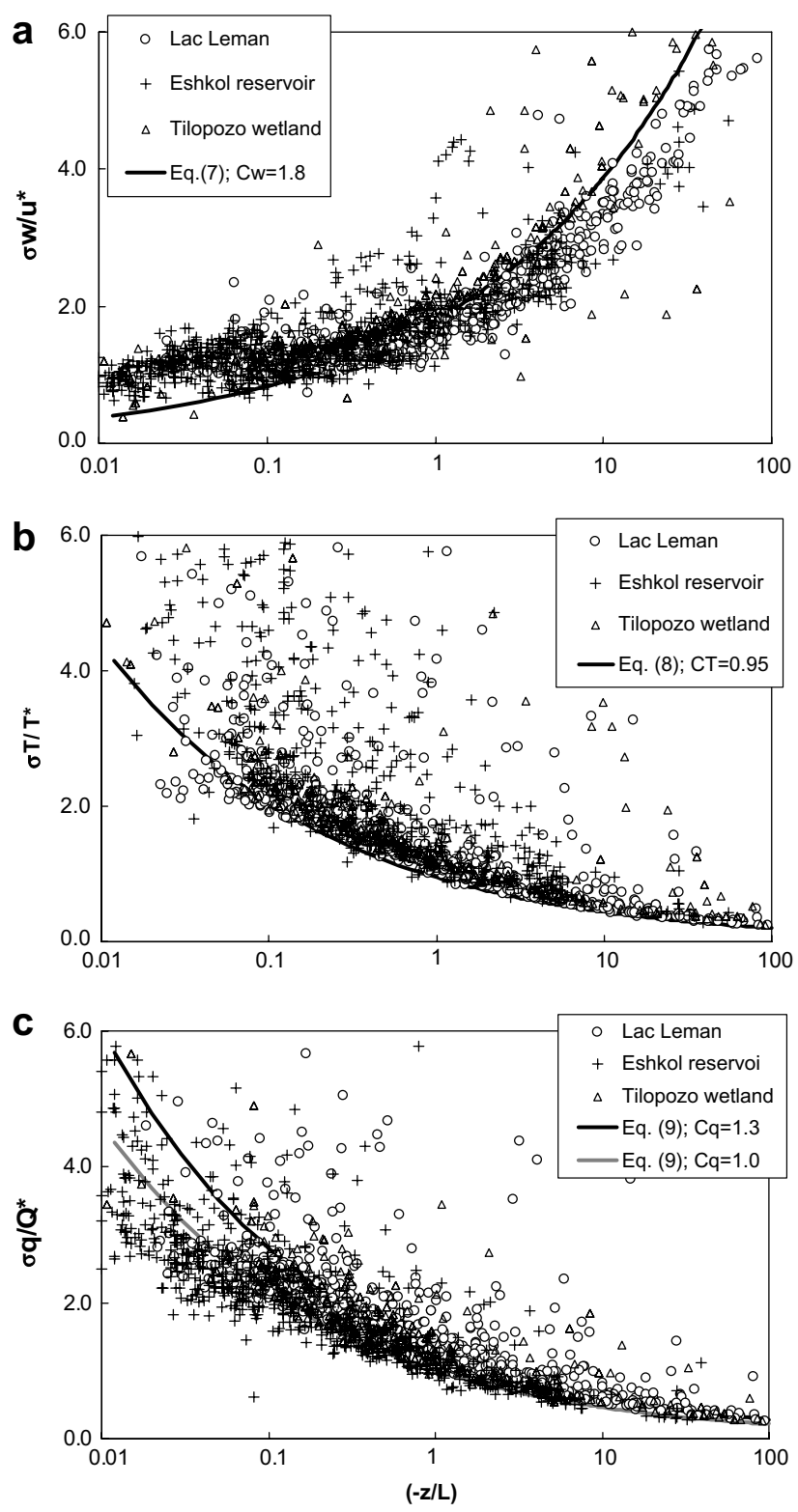

Fig. 5. The scaled standard deviations of the measured fluctuations in (a) vertical wind velocity, $\sigma_{w} / u^{*}$, (b) temperature, $\sigma_{T} / T^{*}$, and (c) water vapour, $\sigma_{q} / Q^{*}$, plotted against the dimensionless stability parameter $(-z / L)$ for the three sites. The solid lines represent the corresponding expressions in (7)-(9).

dancy in temperature and water vapor concentration profiles in the atmosphere, precise estimates of the diffusivities are not possible. Also, it is impossible to estimate these diffusivities for the wetland, for which surface temperature was not available. Hence, we only concentrate on the transport efficiency here.

With respect to transport efficiencies for temperature and humidity (Fig. 6), the three sites had similar distributions of the ratios $\frac{R_{w T} T}{R_{w g}}$. For the wetland, the ensemble-averaged $\frac{R_{w T} T}{R_{w q}} \sim 1$, for the lake $\frac{R_{w T}}{R_{w q}}>1$ while for the reservoir $\frac{R_{w T}}{R_{w q}}<1$.

${ }^{\text {wq }}$ The ratio of $C_{T}$ to $C_{q}((8)$ and (9)), which is equal to $R_{w q} / R_{w T}((12)$ and (13)), is plotted in Fig. 7 as a function

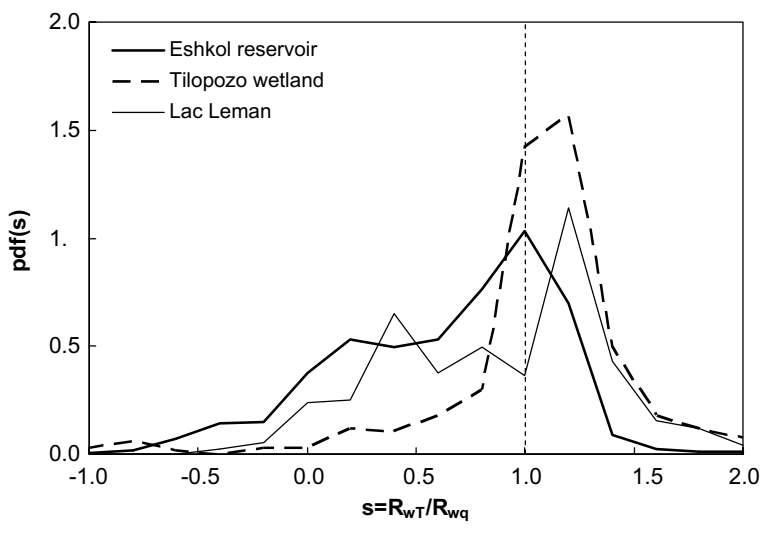

Fig. 6. The probability density functions (pdf) of $\frac{R_{w T}}{R_{w q}}$ for the experimental periods at the three sites.

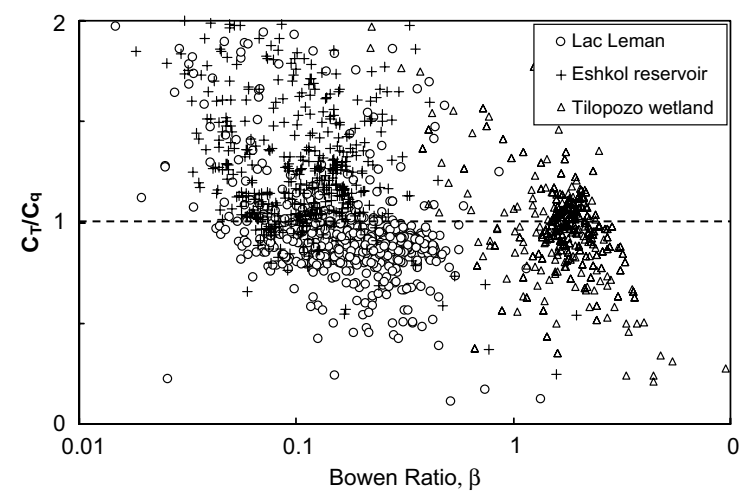

Fig. 7. Computed values of $\frac{C_{T}}{C_{q}}$ versus the Bowen ratio, $\beta$, for all the data.

of the Bowen ratio. It appears that for the reservoir, $C_{T}>C_{q}$, for the lake, $C_{T}<C_{q}$, and for the wetland $C_{T} \sim C_{q}$. We qualitatively explore next the cause of these differences in $C_{T} / C_{q}$.

\subsection{Discussion}

To explore possible mechanisms as to why $C_{T} / C_{q}$ are not consistent across all three sites, we consider the simplified scalar variance budget given by

$\bar{U}(z) \frac{\partial \overline{c^{\prime 2}}}{\partial x} \approx-2 \overline{w^{\prime} c^{\prime}} \frac{\partial \bar{C}}{\partial z}-2 \varepsilon_{c}$.

This budget is valid for stationary flows in the absence of any subsidence and for conditions when the flux-transport terms are neglected relative to the production term. A standard model for the scalar variance dissipation rate is given by

$\varepsilon_{c}=\frac{C_{\varepsilon}}{\tau} \sigma_{c}^{2}$

where $\tau$ is a relaxation time scale (defined as the ratio of turbulent kinetic energy to its dissipation rate), and $C_{\varepsilon}$ is a similarity constant (see [46,47]). Hence, with these approximations, 
$\sigma_{c}^{2}=\frac{\tau}{C_{\varepsilon}}\left(-\overline{w^{\prime} c^{\prime}} \frac{\partial \bar{C}}{\partial z}-\frac{1}{2} \bar{U} \frac{\partial \sigma_{c}^{2}}{\partial x}\right)$.

Even if we adopt MOST scaling for the production term, given as

$-\overline{w^{\prime} c^{\prime}} \frac{\partial \bar{C}}{\partial z}=u_{*} C_{*} \frac{C_{*}}{k z} \phi_{c}(z / L)$,

where $\phi_{c}(z / L)$ is the flux-gradient similarity function, we still obtain differences between $C_{T}$ and $C_{q}$ as we show next.

Normalizing the above variance budget by $C_{*}^{2}$ results in

$\frac{\sigma_{c}^{2}}{C_{*}^{2}}=\frac{\tau}{C_{\varepsilon}} \frac{u_{*}}{k z} \phi_{c}(z / L)-\frac{\tau}{C_{\varepsilon}} \frac{1}{2} \frac{\bar{U}}{C_{*}^{2}} \frac{\partial \sigma_{c}^{2}}{\partial x}$

Here, the first-term on the right-hand side can be made to recover MOST scaling for scalar variances after specifying appropriate $C_{\varepsilon}$ and $\tau$ (see [46]), and the second term is the 'perturbation' induced by advection to the flux-variance similarity theory. The flux-variance similarity function, in the presence of advection, can now be expressed as

$$
\begin{aligned}
\frac{\sigma_{c}}{C_{*}} & =\left(\frac{\tau}{C_{\varepsilon}} \frac{u_{*}}{k z} \phi_{c}(z / L)-\frac{\tau}{C_{\varepsilon}} \frac{1}{2} \frac{\bar{U}}{C_{*}^{2}} \frac{\partial \sigma_{c}^{2}}{\partial x}\right)^{1 / 2} \\
& =C_{c}^{\mathrm{eff}}\left(\frac{-z}{L}\right)^{-1 / 3}
\end{aligned}
$$

where $C_{c}$ is a flux-variance similarity constant $\left(=C_{T}\right.$ or $C_{q}$; (8) and (9)) and $C_{c}^{\text {eff }}$ is the data-derived value of $C_{c}$ for advective (or non-ideal) conditions obtained from fitting the data to MOST similarity functions. When replacing the scalar $c$ with temperature and water vapor, it can be shown that

$\frac{C_{T}^{\text {eff }}}{C_{q}^{\text {eff }}}=\frac{\left(\frac{\tau}{C_{\varepsilon}} \frac{u_{*}}{k z} \phi_{T}(z / L)-\frac{\tau}{C_{\varepsilon}} \frac{1}{2} \frac{\bar{U}}{T_{*}^{2}} \frac{\partial \sigma_{T}^{2}}{\partial x}\right)^{1 / 2}}{\left(\frac{\tau}{C_{\varepsilon}} \frac{u_{*}}{k z} \phi_{q}(z / L)-\frac{\tau}{C_{\varepsilon}} \frac{1}{2} \frac{\bar{U}}{Q_{*}^{2}} \frac{\partial \sigma_{q}^{2}}{\partial x}\right)^{1 / 2}}$.

When the flow is from dry to wet, $\partial \sigma_{T}^{2} / \partial x<0\left(\sigma_{T}\right.$ is much larger over the hotter surface when compared to the wetter surface), and $\partial \sigma_{q}^{2} / \partial x>0\left(\sigma_{q}\right.$ is much lower over the dry surface when compared to the wet surface). Hence, even if $\phi_{T}(z / L)=\phi_{q}(z / L)$, advection alone can lead to $C_{T}^{\text {eff }} / C_{q}^{\text {eff }}>1$, which is opposite to what Katul and Hsieh [28] derived. Katul and Hsieh [28] demonstrated that the active role of temperature alone, for idealized atmospheric flows, leads to

$\frac{C_{T}}{C_{q}} \sim \frac{\overline{T^{\prime} q^{\prime}}}{\sigma_{T} \sigma_{q}}<1$.

The arguments in Katul and Hsieh [28] were strictly based on dissimilarity in the buoyancy term in the heat- and water vapor scalar- flux budget equations, given by

$$
\begin{aligned}
& \frac{\partial \overline{w^{\prime} T^{\prime}}}{\partial t}=\cdots+\frac{g}{\bar{T}} \overline{T^{\prime} T^{\prime}} \\
& \frac{\partial \overline{w^{\prime} q^{\prime}}}{\partial t}=\cdots+\frac{g}{\bar{T}} \overline{T^{\prime} q^{\prime}}
\end{aligned}
$$

We find here that the measured $C_{T} / C_{q}$ is the result of two opposing effects: the active role of temperature that can lead to $C_{T} / C_{q}<1$ (for unstable conditions), and the role of advection that can lead to $C_{T} / C_{q}>1$ here. We can now interpret the results of $C_{T} / C_{q}$ from the three sites (as well as the relative transport efficiencies) as follows:

1. For the lake, advection is small, and $C_{T} / C_{q}<1$ primarily due to the active role of temperature (as predicted by Katul and Hsieh [28] and evidenced by Fig. 7).

2. For the reservoir, the role of advection is sufficiently large to overcome the active role of temperature predicted by Katul and Hsieh [28] resulting in $C_{T} / C_{q}>1$ as evidenced by Fig. 7 .

3 . For the wetland, the two effects are partially compensating and $C_{T} / C_{q} \sim 1$ evidenced by the scatter in Fig. 7 around unity.

Again, this analysis is only qualitative and intended to demonstrate how advection may perturb $C_{T} / C_{q}$ from unity. The three sites here experience different degrees of advection, and the analysis above is consistent (at least in trend) with $C_{T}^{\text {eff }} / C_{q}^{\text {eff }}$ derived from the data at the three sites.

\section{Summary and conclusion}

The flow statistics of heat and water vapor, most pertinent to lake evaporation measurements, were explored over three water bodies differing in climate, thermal inertia and degree of advective conditions. The three systems included are Lac Léman in Switzerland (high thermal inertia, homogeneous conditions with no appreciable advection), Eshkol reservoir in Israel (intermediate thermal inertia, frequent strong advective conditions) and Tilopozo wetland in Chile (low thermal inertia, frequent but moderate advection). The data analysis focused on how similarity constants for the flux-variance approach, $C_{T} / C_{q}$ (also shown to be a surrogate for the transport efficiencies, $R_{w T} / R_{w q}$ ), are perturbed from their idealized state - the latter predicted from Monin-Obukhov similarity theory (MOST). We found that when advection is small and thermal inertia is large, $C_{T} / C_{q}<1$ (or $R_{w T} / R_{w q}>1$ ) primarily due to the active role of temperature (as reported by earlier studies). This finding is also consistent with a large number of field studies where no significant advection was reported. However, when advection is significantly large, the data here suggest that $C_{T} / C_{q}>1 \quad\left(\right.$ or $\left.R_{w T} / R_{w q}<1\right)$. Finally, we showed that when advection is moderate and thermal inertia is low, $C_{T} / C_{q} \sim 1$. This equality, while consistent with MOST, is due to the fact that moderate advection tends to increase $C_{T} / C_{q}$ above unity while the active role of temperature tends to lower $C_{T} / C_{q}$ below unity. These arguments were shown to be consistent with a simplified scaling analysis derived from the scalar variance budget equation. This variance budget analysis explained how advection qualitatively perturbs MOST scaling. 
Broader impacts of this work are threefold: (1) on the theoretical side, we have shown how advection categorically perturbs MOST scaling, and hence, it is now possible to assess qualitatively what biases are expected when using MOST to predict evaporation, (2) on the experimental side, much of the earlier data were primarily collected over bare soils and vegetated areas, and hence, the current study fills an important gap by including data from small water surfaces such as reservoirs and lakes routinely subjected to advective conditions, (3) the analysis here invites future large eddy simulation 'experiments' to explore the interplay between the active role of temperature (via buoyancy) and advection on the similarity between heat and water vapor transport.

\section{Acknowledgement}

This study was performed when S. Assouline and S. Tyler visited EPFL (Switzerland) and they thank the School of Architecture, Civil, and Environmental Engineering for their hospitality. The authors are grateful to Beni Teltsh and Diego Berger from the Watershed Unit of Mekorot Ltd., for their collaboration and support at Eshkol, to Ulrich Lemmin, Hendrick Huwald, and John Selker for their contributions to the Lake Geneva experiment, to Cynthia Lin and Stephanie Kampf for their efforts in the Tilopozo wetland study, and to Minera Escondida and Sociedad Quimica y Minera de Chile for their logistical support during the Tilopozo campaigns.

This research was supported by Mekorot, Ltd. (The Israel National Water Company), the Swiss National Science Foundation, Research Grant No. IS3861-06 from BARD, the United States-Israel Binational Agricultural Research and Development Fund, and the U.S. National Science Foundation Grant (NSF EEC01-39659, NSF-EAR-0628432, NSF-EAR-06-35787). This support is gratefully acknowledged.

\section{References}

[1] Albertson JD, Parlange MB, Katul GG, Chu C-R, Stricker H, Tyler S. Sensible heat flux from arid regions: A simple-flux-variance method. Water Resour Res 1995;31:969-73.

[2] Andreas EL, Hill R, Gosz J, Moore D, Otto W, Sarma A. Statistics of surface layer turbulence over terrain with meter-scale heterogeneity. Boundary-Layer Meteorol 1998;86:379-408.

[3] Asanuma J, Brutsaert W. Turbulence variance characteristics of temperature and humidity in the unstable atmospheric surface layer above a variable pine forest. Water Resour Res 1999;35: $515-21$.

[4] Assouline S. Estimation of lake hydrologic budget terms using the simultaneous solution of water, heat and salt balances and a Kalman filtering approach - application to Lake Kinneret. Water Resour Res 1993;29:3041-8.

[5] Assouline S, Mahrer Y. Evaporation from Lake Kinneret 1. Eddy correlation measurements and energy budget estimate. Water Resour Res 1993;29:901-10.

[6] Beljaars ACM, Schotanus P, Nieuwstadt FTM. Surface layer similarity under non-uniform fetch conditions. J Clim Appl Meteorol 1983;22:1800-10.
[7] Bolsenga SJ. Estimating energy budget components to determine Lake Huron evaporation. Water Resour Res 1975;11:661-6.

[8] Bou-Zeid E, Meneveau C, Parlange MB. Large-eddy simulation of neutral atmospheric boundary layer flow over heterogeneous surfaces: Blending height and effective surface roughness. Water Resour Res 2004;40:W02505.

[9] Bou-Zeid E, Parlange MB, Meneveau C. On the parameterization of surface roughness at regional scales. J Atmos Sci 2007;64:216-27.

[10] Bowen IS. The ratio of heat losses by conduction and by evaporation from any water surface. Phys Rev 1926;27:779-87.

[11] Brutsaert W. Evaporation into the atmosphere: theory, history, and Applications. Dordrecht: D. Reidel; 1982.

[12] Brutsaert W. Land-surface water vapor and sensible heat flux: Spatial variability, homogeneity, and measurement scales. Water Resour Res 1998;34:2433-42.

[13] De Bruin HAR, Bink NI, Kroon LJM. Fluxes in the surface layer under advective conditions. In: Schmugge TJ, Andre JC, editors. Workshop on land surface evaporation, measurement and parameterization. New York: Springer-Verlag; 1991. p. 157-69.

[14] De Bruin HAR, Kohsiek W, van den Hurk BJJM. A verification of some methods to determine the fluxes of momentum, sensible heat and water vapour using standard deviation and structure parameters of scalar meteorological quantities. Boundary-Layer Meteorol 1993;63:231-57.

[15] De Bruin HAR, van den Hurk BJJM, Kroon LJM. On the temperature-humidity correlation and similarity. Boundary-Layer Meteorol 1999;93:453-68.

[16] Denmead OT, McIlroy IC. Measurement of non-potential evaporation from wheat. Agric Meteor 1970;7:285-302.

[17] Eichinger WE, Cooper DI, Parlange MB, Katul GG. The application of a scanning water Raman-Lidar as a probe of the atmospheric boundary layer. IEEE Trans Geosci Remote Sensing 1993;31:70-9.

[18] Eichinger WE, Parlange MB, Katul GG. Lidar measurements of the dimensionless humidity gradient in an unstably stratified atmosphere. In: Lakshmi V, Albertson J, Schaake J, editors. Models and observations of land-atmosphere interaction. American Geophysical Union; 2001. p. 7-13.

[19] Hill RJ. Implications of Monin-Obukhov similarity theory for scalar quantities. J Atmos Sci 1989;46:2236-47.

[20] Högström U, Smedman-Högström AS. Turbulence mechanisms at an agricultural site. Boundary-Layer Meteorol 1974;7:373-89.

[21] Horst T. Corrections to sensible and latent heat flux measurements. NCAR/AtmosphericTechnology Division. 2003. Available from: http://www.atd.ucar.edu/rtf/facilities/isff/heat fluxes.shtml.

[22] Hsieh CI, Katul GG, Scheildge J, Sigmon J, Knoerr KR. Estimation of momentum and heat fluxes using dissipation and flux-variance methods in the unstable surface layer. Water Resour Res 1996;32:2453-62.

[23] Kader BA, Yaglom AM. Mean fields and fluctuation moments in unstably stratified turbulent boundary layers. J Fluid Mech 1990;212:637-62.

[24] Kampf SK, Tyler SW, Ortiz CA, Munoz JF, Adkins PL. Evaporation and land surface energy budget at the Salar de Atacama, Northern Chile. J Hydrol 2005;310:236-52.

[25] Katul GG, Parlange MB. A Penman-Brutsaert model for wet surface evaporation. Water Resour Res 1992;28:121-6.

[26] Katul GG, Parlange MB. On the active-role of temperature in surface-layer turbulence. J Atmos Sci 1994;51:2181-95.

[27] Katul GG, Goltz SM, Hsieh CI, Cheng Y, Mowry F, Sigmon J. Estimation of surface heat and momentum fluxes using the fluxvariance method above uniform and non-uniform terrain. BoundaryLayer Meteorol 1995;74:237-60.

[28] Katul GG, Hsieh C-I. A note on the flux-variance similarity relationships for heat and water vapour in the unstable atmospheric surface layer. Boundary-Layer Meteorol 1999;90:327-38.

[29] Kroon LJM, DE Bruin HAR. The Crau field experiment - turbulent exchange in the surface layer under conditions of strong local advection. J Hydrol 1995; 166:327-51. 
[30] Lamaud E, Irvine M. Temperature-humidity dissimilarity and heatto-water-vapour transport efficiency above and within a pine forest canopy: the role of the Bowen ratio. Boundary-Layer Meteorol 2006; 120:87-109.

[31] Lang ARG, McNaughton KG, Fazu C, Bradley EF, Ohtaki E. Inequality of eddy transfer coefficients for vertical transport of sensible and latent heat under advective inversions. Boundary-Layer Meteorol 1983;25:25-41.

[32] Lenters JD, Kratz TK, Bowser CJ. Effects of climate variability on lake evaporation: results from a long-term energy budget study of Sparkling Lake, northern Wisconsin (USA). J Hydrol 2005;308: 168-95.

[33] Mahrer Y, Rytwo G. Modelling and measuring evapotranspiration in a daily drip irrigated cotton field. Irrig Sci 1991;12:13-20.

[34] McCartney J. Hydraulic and hydrochemical interactions in the Tilopozo groundwater, Region II, Chile (Master Thesis). University of Technology, Sydney, July 2002.

[35] Monin AS, Obukhov AM. Basic laws of turbulent mixing in the ground layer of the atmosphere. Tr Geofiz InstAkad Nauk SSSR 1954;151:163-87.

[36] Monin AS, Yaglom AM. In: Lumley JL, editor. Statistical fluid mechanics: mechanics of turbulence, vol. 1. Cambridge, MA: MIT Press; 1971. p. 769.

[37] Ohtaki E. On the similarity in atmospheric fluctuations of carbon dioxide, water vapor and temperature over vegetated fields. Boundary-Layer Meteorol 1985;2:25-37.

[38] Padro J. An investigation of flux-variance methods and universal functions applied to three land land-use type in unstable conditions. Boundary-Layer Meteorol 1993;66:413-25.

[39] Pahlow M, Parlange MB, Porte-Agel F. On Monin-Obukhov similarity in the stable atmospheric boundary layer. Boundary-Layer Meteorol 2001;99:225-48.

[40] Panofsky HA, Dutton JA. Atmospheric turbulence. New York: John Wiley; 1984. 397 pp.

[41] Parlange MB, Eichinger WE, Albertson JD. Regional-scale evaporation and the atmospheric boundary-layer. Rev Geophys 1995;33: 99-124.

[42] Parlange MB, Albertson JD, Eichinger WE, Cahill AT, Jackson TJ, Kiely G, Katul GG. Evaporation: Use of fast-response turbulence sensors, Raman Lidar, and passive microwave remote sensing. In: Parlange MB, Hopmans JW, editors. Vadose zone hydrology: cutting across disciplines. Oxford University Press; 1999. p. 454.

[43] Priestley CHB, Taylor RJ. On the assessment of surface heat flux and evaporation, Mon. Weather Rev 1972;106:81-92.

[44] Papaioannou G, Jacovides C, Kerkides P. Atmospheric stability effects on eddy transfer coefficients and on Penman's evaporation estimates. Water Resour Manage 1989;3:315-22.
[45] Sanchez A, Morales R. Las regions de Chile Espacio Fisico y humano-economico. SA, Santiago de Chile: Editorial Universitaria; 1990.

[46] Siqueira M, Katul GG. Estimating heat sources and fluxes in thermally stratified canopy flows using higher-order closure models. Boundary-Layer Meteorol 2002;103:125-42.

[47] Siqueira MB, Katul GG, Lai CT. Quantifying net ecosystem exchange by multilevel ecophysiological and turbulent transport models. Adv Water Resour 2002;25:1357-66.

[48] Smedem-Hörgström A-S. Temperature and humidity spectra in the atmospheric surface layer. Boundary-Layer Meteorol 1973;3:329-47.

[49] Sorbjan Z. Structure of the atmospheric boundary layer. Englewood Cliffs, NJ: Prentice Hall; 1989. 317 pp.

[50] Stannard DI, Rosenberry DO. A comparison of short-term measurements of lake evaporation using eddy correlation and energy budget methods. J Hydrol 1991;122:15-22.

[51] Stull RB. An introduction to boundary layer meteorology. The Netherlands: Kluwer; 1988.

[52] Sugita M, Kawakubo N. Surface and mixed-layer variance methods to estimate regional sensible heat flux at the surface. Boundary-Layer Meteorol 2003;106:117-45.

[53] Swinbank WC. The measurement of vertical transfer of heat and water vapor by eddies in the lower atmosphere. J Meteorol 1951;8:135-45.

[54] Swinbank WC, Dyer AJ. An experimental study in micrometeorology. Quart J Roy Meteorol Soc 1967;93:494-500.

[55] Tanner BD, Greene JP. Measurement of sensible heat and water vapor fluxes using eddy correlation methods. Logan, USA: Campbell Scientific Inc.; 1989.

[56] Tilleman JE. The indirect determination of stability, heat and momentum fluxes in the atmospheric boundary layer for simple scalar variables during unstable conditions. J Appl Meteorol 1972;11:783-92.

[57] Van Dijk A, Moene AF, De Bruin HAR. The principles of surface flux physics: theory, practice and description of the ECPACK library. Internal Report 2004/1, Meteorology and Air Quality Group, Wageningen University, Wageningen, the Netherlands, 2004. 99 pp.

[58] Verma SB, Rosenberg NJ, Blad BL. Turbulent exchange coefficients for sensible heat and water vapor under advective conditions. J Appl Meteorol 1978;17:330-8.

[59] Warhaft Z. Heat and moisture fluxes in the stratified boundary layer. Quart J Roy Meteorol Soc 1976;102:703-6.

[60] Wyngaard JC, Cote OR, Izumi Y. Local free convection, similarity and the budgets of shear stress and heat flux. J Atmos Sci 1971;28:1171-82.

[61] Zhang H, Chen J. Turbulence structure in unstable conditions over various surfaces. Boundary-Layer Meteorol 2001;100:243-61. 